\title{
Pseudomonas aeruginosa ventilator associated pneumonia: improved outcomes with earlier follow-up
}

\author{
Elpis Giantsou ${ }^{1,2}$, Nikolaos Liratzopoulos ${ }^{1}$, Eleni Efraimidou ${ }^{1}$, Konstantinos I. Manolas $^{1}, \mathrm{~J}$. \\ Duncan Young ${ }^{2}$
}

\footnotetext{
${ }^{1}$ Intensive Care Unit, Demokritus University of Thrace, Greece

${ }^{2}$ Adult intensive Care Unit, John Radcliffe Hospital, Oxford, United Kingdom; elpisgiantsou@yahoo.com
}

Received 27 October 2009; revised 16 December 2009; accepted 17 December 2009.

\begin{abstract}
It is not clear what is the appropriate timing to follow-up patients with ventilator-associated pneumonia (VAP) and Clinical Pulmonary Infection Score > 6 between days 3-5 of an appropriate antibiotic treatment. We studied 122 patients with Pseudomonas aeruginosa VAP. A follow-up respiratory sample was collected on days three or five ( "day-three" and "day-five" group ) and treatment was modified 48h later. Molecular typing identified super-infections or persistence. For serial data another respiratory sample was collected, on day three from the "day-five" group and on day five from the "day-three" group. Sixty patients, in the "daythree" group compared to 62 in the "day-five" group, had reduced fourteen-day mortality ( $18.3 \%$ and $38.7 \% ; p=0.01$ ) and fewer days in intensive care unit (17.2 \pm 4.3 compared to 27.3 $\pm 4.7, p<0.05$ ). Eighteen patients of the "dayfive" group were diagnosed with super-infec tion and 22 with persistence on day five, of whom 14 and 19 had been having these patterns since day three. For patients with Pseudomonas aeruginosa VAP and Clinical Pulmonary Infection Score $>6$, improved fourteen-day mortality and shorter duration of stay in health-care facilities were observed with earlier follow-up.
\end{abstract}

Keywords: Ventilator-Associated Pneumonia; Clinical Pulmonary Infection Score; Pseudomonas Aeruginosa

\section{INTRODUCTION}

In addition to its value in diagnosing ventilator-associated pneumonia (VAP), the Clinical Pulmonary Infection Score (CPIS) has other uses [1]. Initial values of CPIS may guide the duration of antibiotic therapy for patients with VAP [2], while serial measurements may identify patients as potentially un-responsive to antibiotic therapy, when the value of the score is above six from day three to day five of antibiotic treatment [3]. Further investtigation of patients identified as potentially un-responsive should ensure that the administered antimicrobials are appropriate and that extra-pulmonary infections and non-infectious conditions are not involved $[4,5]$. When the lung remains the suspected focus of infection, the next step should involve a follow-up respiratory sample to investigate treatment failure [6]. However, it is not clear from the data available [3,7] what is the appropriate timing to collect a follow-up respiratory sample from patients with VAP, in whom CPIS remains $>6$, between days three to five of antibiotic treatment. Should the follow-up respiratory sample be collected on day three or a little later?

The objective was to evaluate an earlier compared with a later timing to retrieve respiratory pathogens and determine treatment failure, for patients with initially appropriately treated Pseudomonas aeruginosa (P. Aeruginosa) VAP, in whom the simplified CPIS [3] remained $>6$ between days 3-5 of antibiotic therapy.

\section{MATERIALS AND METHODS}

The study was conducted at the University Hospital of Thrace, during a 48-month period. Patients were entered into the study if they met all the following: clinical suspicion for VAP [1]; two identical positive solely for P. aeruginosa quantitative cultures, one of tracheal aspirate and one of bronchoalveolar lavage (BAL) (thresholds of $>10^{6}$ and $>10^{4}$ colony-forming units $/ \mathrm{ml}$, respectively); and simplified CPIS $>6$ [3] between days 3-5 of treatment. Patients were excluded if they had received solid organ or bone marrow transplant or had evidence of rapid deterioration within $72 \mathrm{hr}$ of treatment [8]. The diagnostic and therapeutic approach is presented in Figure 1. Initial antibiotic treatment for P. aeruginosa with daily infusion of Amikacin (20mg/kg per day) combined with $6 \mathrm{~h}$ bolus administration of Piperacillin- Tazobactam $(4.5 \mathrm{gm})$ was instigated within $6 \mathrm{~h}$ of bronchoscopy. 


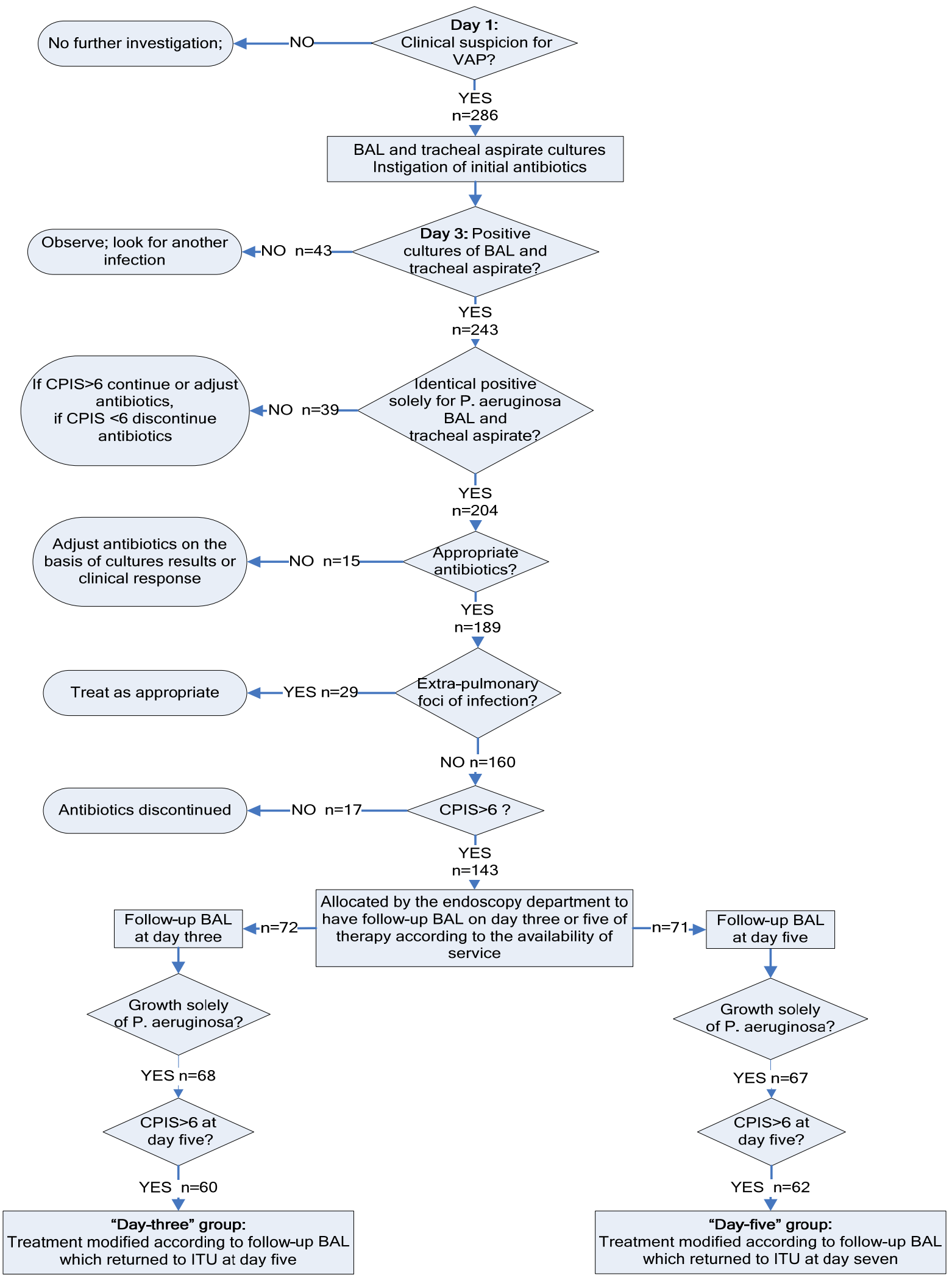

Figure 1. Schematic presentation of the diagnostic and therapeutic approach. VAP, ventilator-associated pneumonia; BAL, bronchoalveolar-lavage; P.aeruginosa, Pseudomonas aeruginosa; CPIS, Clinical Pulmonary Infection Score. 

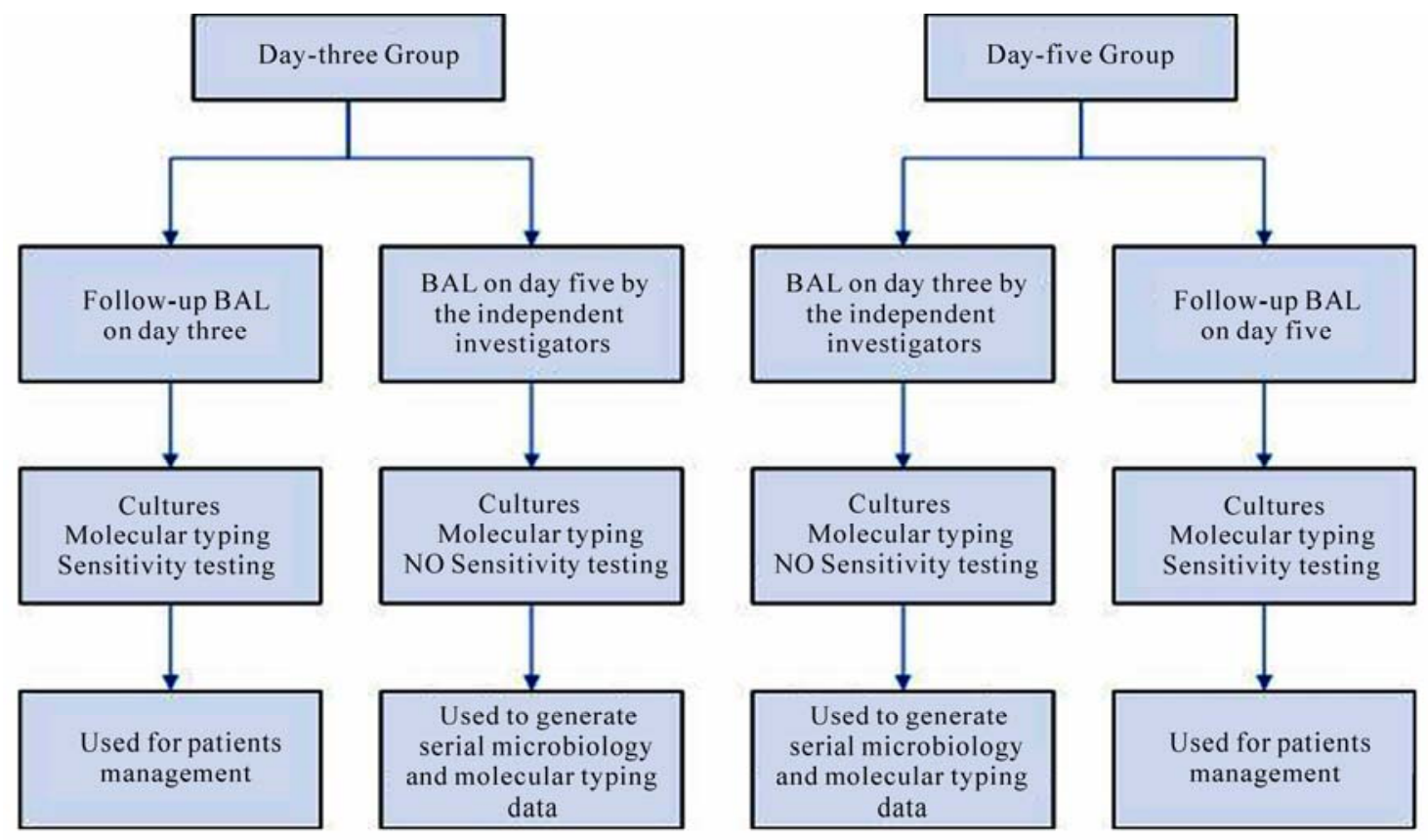

Figure 2. Schematic representation of the approach used for serial microbiology and molecular typing.

The follow-up BAL was collected by the endoscopy group on days three or five as determined by the availability of service and patients shall be referred to as the "day-three" and the "day-five" group respectively. The follow-up BAL cultures and sensitivity tests results returned to the Intensive Care Unit (ICU) 48hr later and were used to modify the antimicrobials. The duration of treatment was 14 days [9].

Pulsed gel electrophoresis was applied to the BAL samples at study entry and follow-up, to identify whether P. aeruginosa isolated at follow-up was superinfection or persistence of the initial isolate. The DNA fragment patterns were interpreted as genetically indistinguishable, closely related or unrelated $[10,11]$. Isolates genetically unrelated to those grown at study entry were considered super-infections, whereas isolates genetically indistinguishable or closely related, were considered persistence.

For serial microbiologic and molecular typing data two independent investigators performed BAL on day three at the "day-five" group and on day five at the "day-three" group (Figure 2). For cost reasons, no sensitivity testing was undertaken for these samples, when $P$. aeruginosa was isolated, because it was previously tested from the same source. If growth, other than P. aeruginosa, was isolated, then patients were excluded and sensitivity was tested. The outcomes evaluated were mortality, SAPS II [12] and SOFA [13] on day 14 , mortality on day 28 , mortality in ICU and hospital, duration of mechanical ventilation and duration of stay in ICU and hospital after VAP. CPIS and organ failures [13] were assessed on day 14.

\section{STATISTICS}

Data were expressed as mean \pm standard deviation (SD) or as percentages of total. Continuous data were compared using Student's t-test. The chi-square test with Yates correction for proportions was used for categorical variables. All tests were two sided. Significance was accepted for $\mathrm{p}<.05$. Data were analyzed using SPSS 11 (SPSS, Chicago, IL).

\section{RESULTS}

The admission and study entry characteristics of 122 patients with P.aeruginosa VAP appear in Table 1. The CPIS score for the "day-three" and the "day-five" group respectively it was $7.33( \pm 0.47)$ vs $7.32( \pm 0.59)$, $\mathrm{p}=0.9$ on day three and $7.08( \pm 0.27)$ vs $7.1(0.42)$, $\mathrm{p}=0.46$ on day five .

Super-infection and persistence rates of $\mathrm{P}$. aeruginosa as revealed by the follow-up BAL are presented in Table 2 and schematically in Figure 3. For both study groups, the strains of $\mathrm{P}$. aeruginosa identified at follow-up as super-infection or persistence at significant counts were resistant to Piperacillin-Tazobactam and sensitive to Meropenem and Amikacin which replaced the initial combination of Piperacillin-Tazobactam with Amikacin. $P$. aeruginosa strains persistent at insignificant counts at follow-up remained sensitive to the initial antibiotics which remained unchanged.

Significantly lower mortality, SAPS II and SOFA were noted on day 14 for the "day-three" group (Table 3). Schematic presentation of mortality and length of 
Table 1. Admission and study entry characteristics.

\begin{tabular}{|c|c|c|c|}
\hline Characteristics & $\begin{array}{l}\text { "day-three" } \\
\text { group } \\
\mathrm{n}=60\end{array}$ & $\begin{array}{l}\text { "day-five" } \\
\text { group } \\
n=62\end{array}$ & $P$ value \\
\hline \multicolumn{4}{|l|}{ On admission } \\
\hline Age, mean ( SD ) & $55.4(11.9)$ & $55.6(13)$ & 0.2 \\
\hline Men, n (\%) & $39(65)$ & $40(64)$ & 0.9 \\
\hline SAPS II, mean, SD & $43.3(5.8)$ & $45.7(6)$ & 0.7 \\
\hline SOFA, mean, SD & $6.7(2.2)$ & $6.5(2.1)$ & 0.8 \\
\hline \multicolumn{4}{|l|}{ Admission, $\mathrm{n}(\%)$} \\
\hline Medical & $33(55)$ & $31(50)$ & 0.8 \\
\hline Emergency surgery & $14(23)$ & $16(26)$ & \\
\hline Elective surgery & $13(22)$ & $15(24)$ & \\
\hline \multicolumn{4}{|l|}{ Reason for MV, n ( \% ) } \\
\hline Status asthmaticus & $7(12)$ & $8(13)$ & 0.9 \\
\hline COPD & $11(18)$ & $10(16)$ & \\
\hline CAP & $9(15)$ & $7(11)$ & \\
\hline Drug overdose & $9(15)$ & $8(13)$ & \\
\hline Abdominal Surgery & $4(7)$ & $5(8)$ & \\
\hline Other surgery & $5(8)$ & $6(10)$ & \\
\hline $\mathrm{CHF}$ & $5(8)$ & $6(10)$ & \\
\hline Neurological emergency & $10(17)$ & $12(19)$ & \\
\hline \multicolumn{4}{|l|}{ On study entry } \\
\hline MV before VAP, mean ( SD ), d & $6.9(1.2)$ & $7(1.2)$ & 0.9 \\
\hline Antibiotics before VAP, n(\%) & $47(78)$ & $46(74)$ & 0.8 \\
\hline SAPS II, mean ( SD ) & $45.3(5.8)$ & $46(6.3)$ & 0.1 \\
\hline SOFA, mean ( SD ) & $6.8(2.1)$ & $6.7(2.3)$ & 0.7 \\
\hline CPIS, mean ( SD ) & $7.68(0.85)$ & $7.6(0.7)$ & 0.8 \\
\hline
\end{tabular}

Abbreviations: SAPS, Simplified Acute Physiology Score; SOFA, Sequential Organ Failure Assessment; MV, Mechanical Ventilation; COPD, Chronic Obstructive Pulmonary Disease; CAP, Community Acquired Pneumonia; CHF, Congestive Heart Failure; VAP, Ventilator-associated pneumonia.

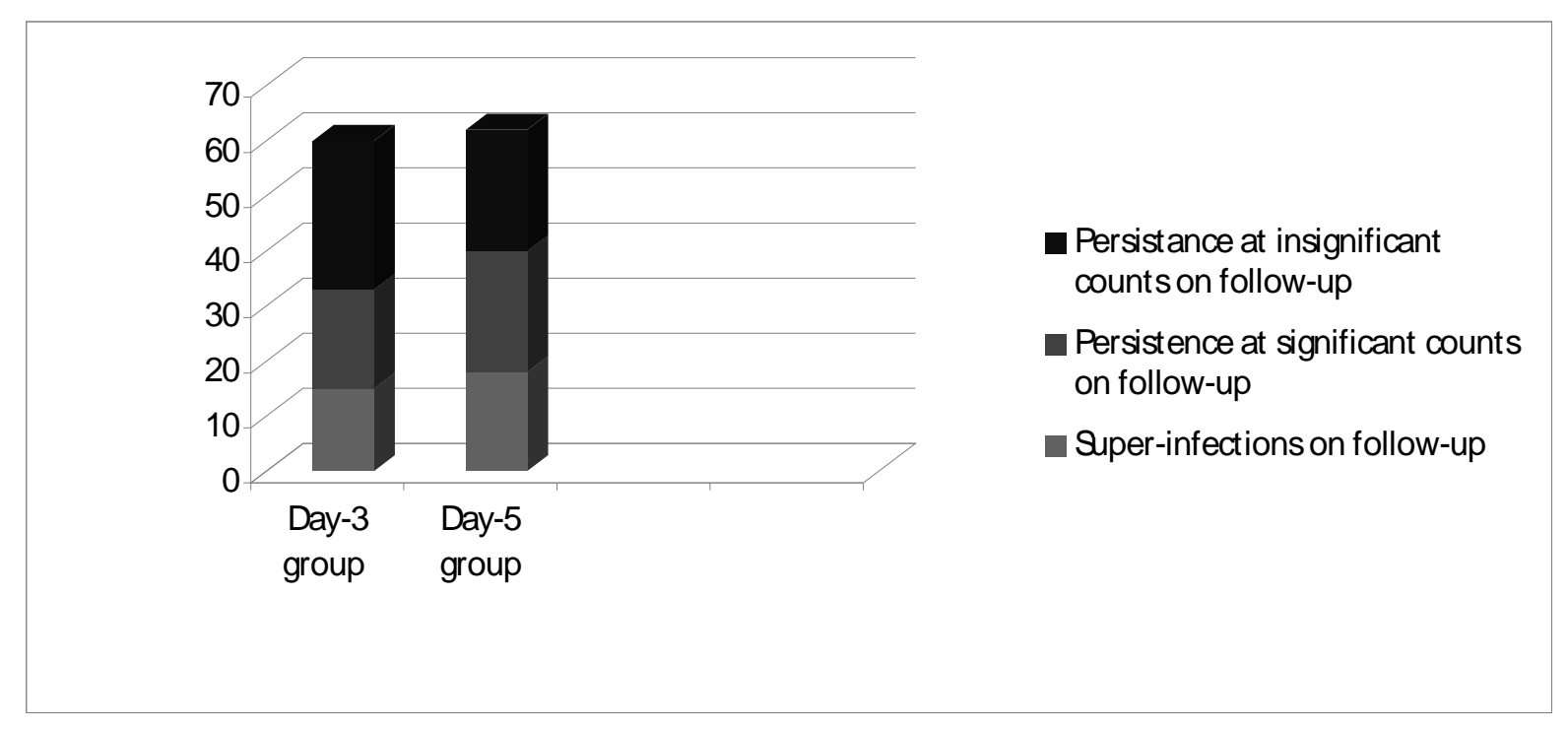

Figure 3. Schematic presentation of P.aeruginosa patterns on follow-up. 
Table 2. P.aeruginosa patterns on follow-up.

\begin{tabular}{|c|c|c|}
\hline "Day- three" group on follow-up, $\mathrm{n}=60$ & $\begin{array}{l}\text { Patients } \\
\text { n ( } \%)\end{array}$ & Final antibiotics \\
\hline Super-infection ${ }^{\mathrm{b}}$ & $15(25)$ & $\mathrm{M} / \mathrm{A}$ \\
\hline Persistence $^{c}$ at significant counts & $18(30)$ & $\mathrm{M} / \mathrm{A}$ \\
\hline Persistence $^{c}$ at insignificant counts & $27(45)$ & $\mathrm{PT} / \mathrm{A}$ \\
\hline \multicolumn{3}{|l|}{ "Day- five" group on follow-up ${ }^{\mathrm{a}}, \mathrm{n}=62$} \\
\hline Super-infection ${ }^{\mathrm{b}}$ & $18(29)$ & $\mathrm{M} / \mathrm{A}$ \\
\hline Persistence $^{c}$ at significant counts & $22(35.5)$ & $\mathrm{M} / \mathrm{A}$ \\
\hline Persistence $^{c}$ at insignificant counts & $22(35.5)$ & $\mathrm{PT} / \mathrm{A}$ \\
\hline
\end{tabular}

Abbreviations: M, Meropenem; A, Amikacin; PT,Piperacillin-Tazobactam.

aThe follow-up BAL was performed on day three of therapy for the "day-three" group and on day five of therapy for the "day-five" group.

${ }^{b}$ These Pseudomonas aeruginosa strains were identified as super-infections, because they were genetically unrelated to the clone isolated at study entry.

${ }^{c}$ These Pseudomonas aeruginosa strains were identified as persistence, because they were closely related or indistinguishable to the clone isolated at study entry.

Table 3. Study outcomes.

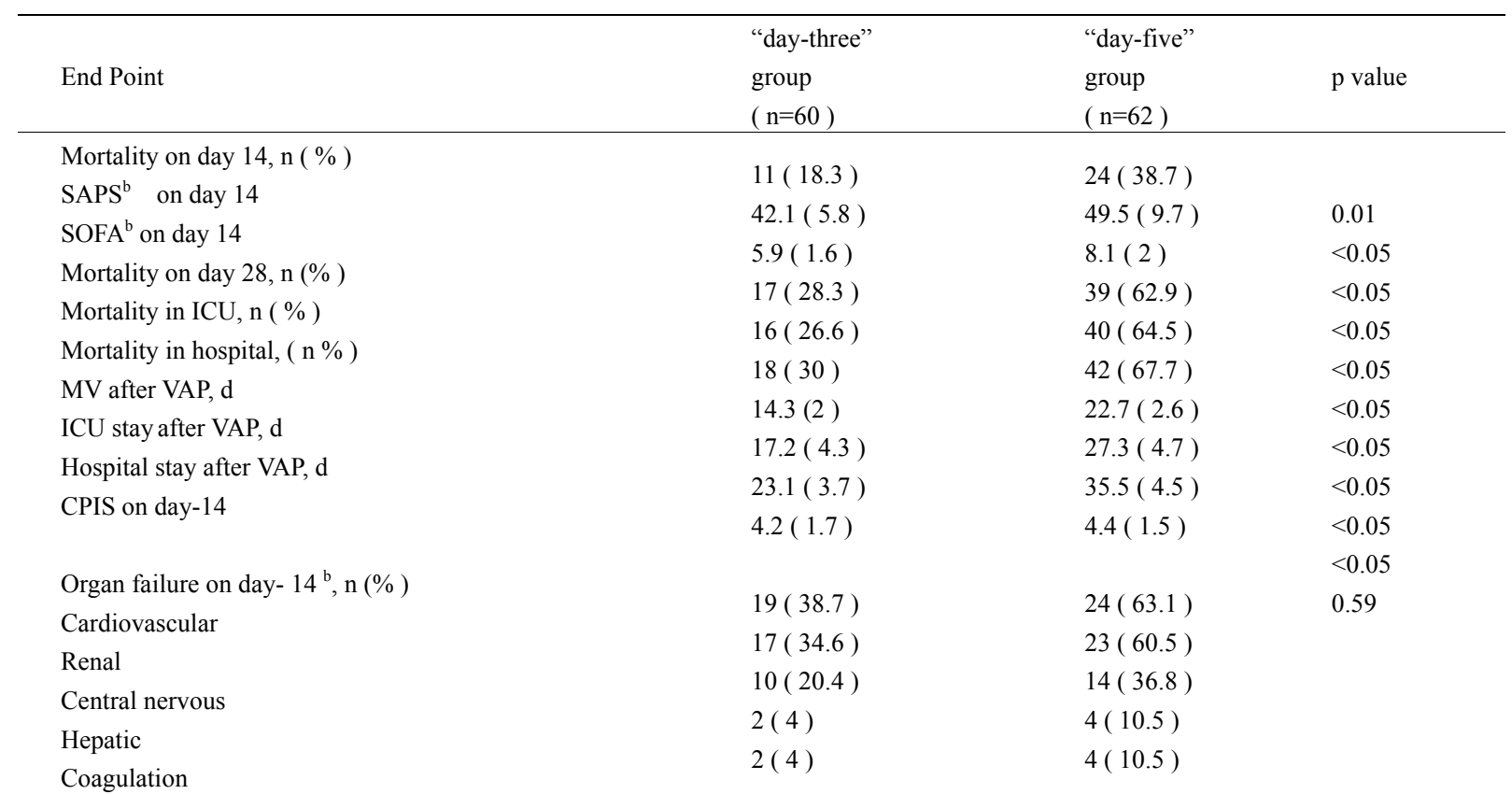

Abbreviations: SAPS, Simplified Acute Physiology Score; SOFA, Sequential Organ Failure Assessment Score; MV, mechanical ventilation; CPIS, Clinical Pulmonary Infection Score ${ }^{b}$ For patients alive on day 14. Values are expressed as mean ( SD ) unless otherwise indicated. Organ failures may not sum up to hundred as some patients may have $>1$.

stay in health care facilities appear in Figure 4.

Eighteen patients of the "day-five" group were diagnosed with super-infection with a new strain of $\mathrm{P}$. aeruginosa at follow-up on day five. Of them 14 had been having super-infection and required treatment change, since day three, as it was diagnosed by the independent investigators on day three (Table 4). Five of the $14(35.7 \%)$ P. aeruginosa strains that were responsible for super-infections in the" day-five" group, were present at insignificant concentrations in the BAL that was performed initially to diagnose VAP. Similarly, for the "day-three" group six of the $15(40 \%)$ superinfections on day 3 were due to overgrowth of P. aeruginosa, that was present in insignificant concentrations in the BAL performed initially to diagnose VAP. The evolution over time of superinfection is presented schematically in Figure 5 for both groups.

Twenty two patients of the "day-five" group were diagnosed at follow-up on day five with persistence at significant counts, of the initially isolated P. aeruginosa 


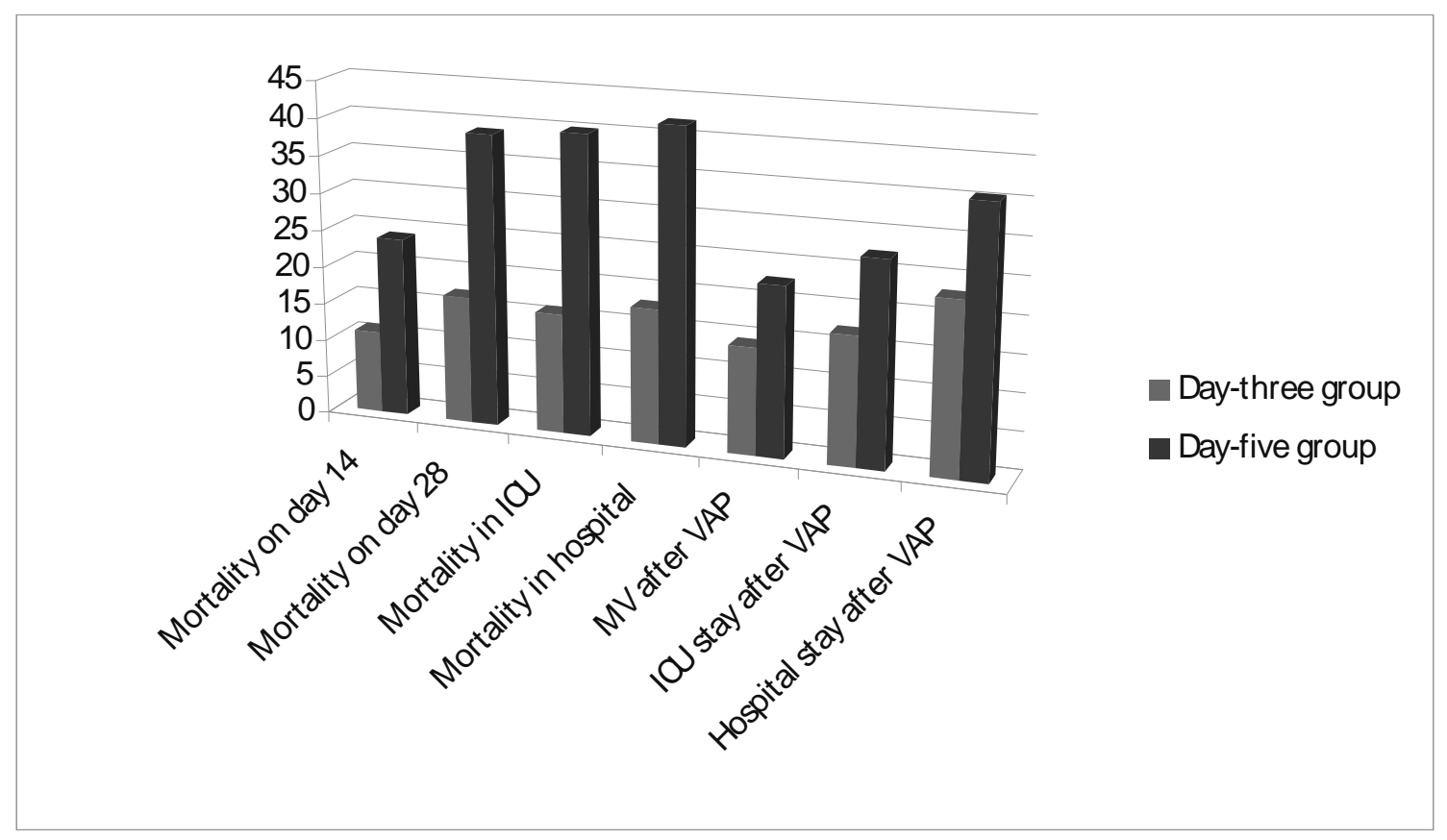

Figure 4. Schematic presentation of mortality and length of stay in health care facilities

Table 4. Super-infection and persistence over time.

\begin{tabular}{lccc}
\hline Patients, $\mathrm{n}(\%)$ & $\begin{array}{c}\text { "day-three" } \\
\text { group }^{\mathrm{a}} \\
(\mathrm{n}=60)\end{array}$ & $\begin{array}{c}\text { "day-five" } \\
\text { group }^{\mathrm{b}} \\
(\mathrm{n}=62)\end{array}$ & $\mathrm{p}$ \\
\hline Super-infections on & & $14(22.5)$ & 0.7 \\
Day three of therapy & $15(25)$ & $18(29)$ & 0.8 \\
Day five of therapy & $20(33.3)$ & $19(30.6)$ & 0.9 \\
Persistence at significant counts on & $18(30)$ & $22(35.4)$ & 0.8 \\
Day three of therapy & $22(36.6)$ & & \\
Day five of therapy & & & \\
\hline
\end{tabular}

${ }^{a}$ For the "day-three" group super-infections and persistence at significant counts on day three of therapy were derived from the follow-up BAL and on day five of therapy from the BAL collected by the independent investigators.

${ }^{b}$ For the "day-five" group super-infections and persistence at significant counts on day three of therapy were derived from the BAL collected by the independent investigators and on day five of therapy from the follow-up BAL.

(Table 4).Of them 19 had been having this pattern and required treatment adjustment, since day three. Fourteen-day mortality for patients of the "day-five" group, who had super-infection or persistence at significant counts since day three and in whom treatment was adjusted on day seven, was 8 of $14(57.1 \%)$ and 11 of $19(58 \%)$ respectively. By contrast, fourteen-day mortality for patients of the "day-three" group, who had superinfection or persistence at significant counts on day three and in whom treatment was adjusted on day five was 3 of $15(20 \%)$ and 4 of $18(22 \%)$ respectively. The evolution over time of persistence at significant counts is presented schematically in Figure 5 for both groups.

\section{DISCUSSION}

In this study, improved fourteen-day mortality, severity scores and duration of stay in ICU and hospital were observed with earlier follow-up and re-institution of an appropriate antibiotic regimen for patients with $P$. aeruginosa VAP, who were initially appropriately treated and in whom CPIS remained $>6$ six between days 3-5 of treatment.

Few data are available, on clinical outcomes with an earlier or a later recognition of treatment failure for patients with initially appropriately treated VAP. Our study showed mortality of $18.3 \%$ for patients re-evaluated on day three and $38.7 \%$ for patients re-evaluated on day five. Montravers et al. reported 35\% mortality, for patients, who on clinical suspicion for VAP were treated appropriately and on day three were microbiologically re-evaluated, to identify and treat super-infections and persistence [7]. 


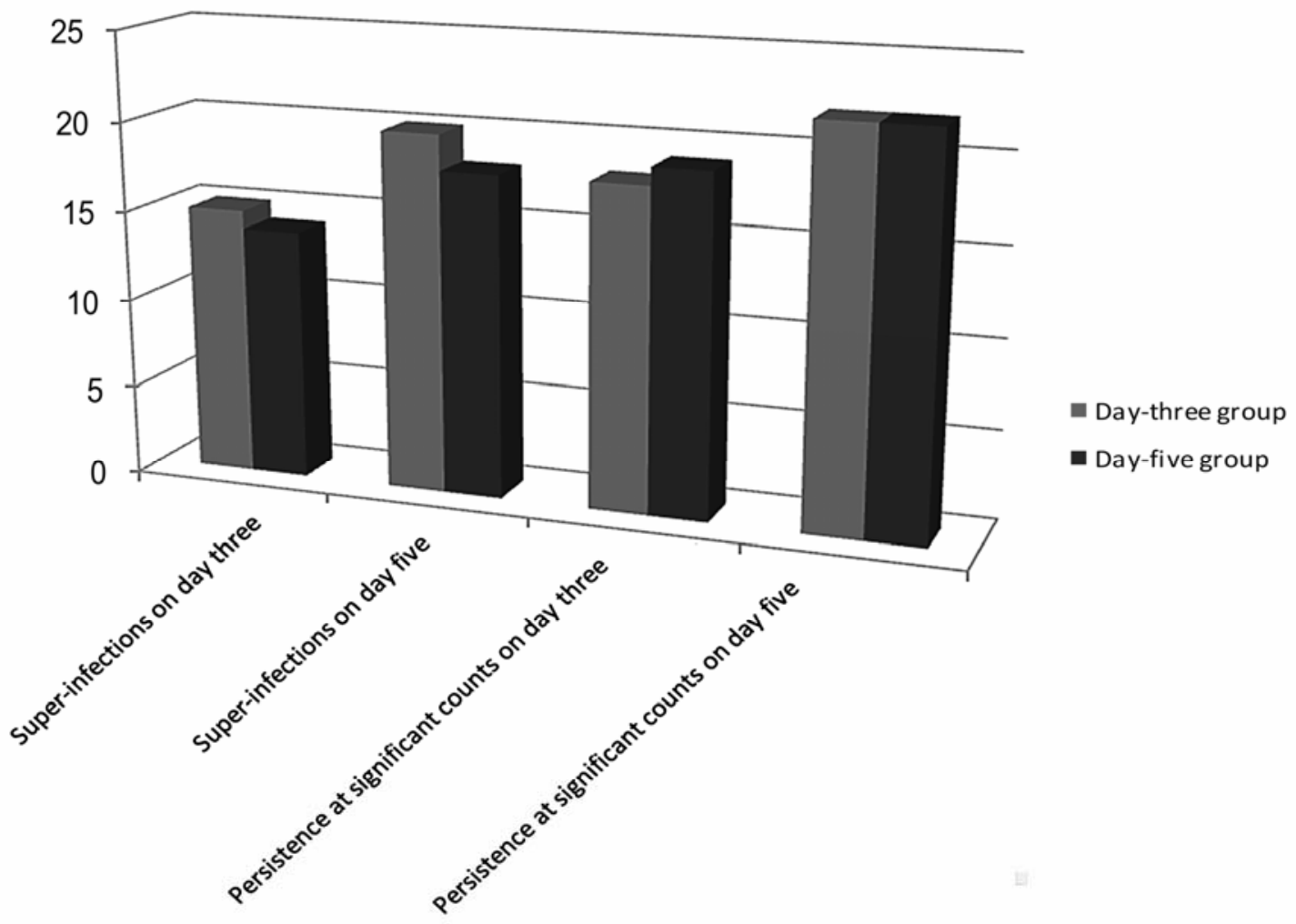

Figure 5. Schematic presentation of super-infection and persistence at significant counts over time

The American Thoracic Society guidelines suggest that the earliest time point to re-assess the antibiotic regimen is day three of treatment [9]. Although, BAL data can optimize antibiotic therapy in VAP, this is translated to improved clinical outcomes when the antibiotics administered on clinical suspicion for VAP are adequate and BAL data become available in a timely manner [14-17]. In our data, both groups had received an appropriate antibiotic therapy on clinical suspicion for VAP, which by day-three became inappropriate due to super-infections and persistence at significant counts. We observed improved outcomes with early recognition and treatment of non-response to therapy. Appropriate antibiotic therapy administered in a timely manner is suggested to be one of the primary determinants of hospital outcome [18] and our data reinforce this view.

Our study has limitations. First, we used the availability of service to determine assignment and not randomization because we could not ensure endoscopy support on the assigned day. This would introduce bias if the availability correlated with aspects of clinical care. Second, the study was necessarily un-blinded, but bias should not have occurred from this as the primary outcome was mortality. Third, it was conducted within a single ICU and a relatively large number of patients were excluded. Therefore the results cannot necessarily be extended to other populations. Fourth, patients in the "day-five" group had CPIS $>6$ from day three of therapy and treatment were modified on day seven. However, the CPIS provided no evidence for deterioration because it was continuously dropping. Finally, our study was not specifically designed to test whether an earlier follow-up is superior to a later one. To answer this question we need a double blind randomized trial.

Although clearly important, an accurate diagnostic technique and an appropriate initial empirical therapy may not be sufficient to reduce mortality in patients with P.aeruginosa VAP $[19,20]$. In our data, improved mortality and shorter duration of stay in health-care facilities were observed with earlier follow-up for patients with P.aeruginosa VAP. This finding suggest that clinicians should have low threshold to re-sample early and if necessary to revise therapy for patients with $\mathrm{P}$. aeruginosa VAP, who failed to reduce CPIS to values below six between days three to five of antibiotic treatment.

\section{REFERENCES}

[1] Niederman, M.S. (2005) The clinical diagnosis of ventilator-associated pneumonia. Respiratory Care, 50, 788-796.

[2] Singh. N., Rogers, P., Atwood, C.W., Wagener, M.M., Yu, V.L. (2000) Short-course empiric antibiotic therapy for patients with pulmonary infiltrates in the intensive care 
unit. Am J Respir Crit Care Med, 162, 505-511.

[3] Luna, L.M., Blanzaco, M., Daniel, D., Niederman, M.S., Matarucco, W., Baredes, N.C., Desmery, P., Palizas, F., Menga, G., Rios, F., Apezteguia, C. (2003) Resolution of ventilator-associated pneumonia, Prospective evaluation of the clinical pulmonary infection score as an early clinical predictor of outcome. Crit Care Med, 31, 676-682.

[4] Ioanas, M., Ewig, S., Torres, A. (2003) Treatment failures in patients with ventilator-associated pneumonia. Infect Dis Clin N Am, 17, 753-771.

[5] Wunderink, R.G. (1995) Ventilator-associated pneumonia, Failure to respond to antibiotic therapy. Clin Chest Med, 16, 173-193.

[6] Menendez, R., Perpina, R., Torres (2005) A. Evaluation of non-resolving and progressive pneumonia. Semin Respir Infect, 18, 103-111.

[7] Montravers, P., Fagon, J.Y., Chastre, J., Lesco, M., Domret, M.C., Trouillet, J.L., Gibert, C. (1993) Follow-up protected specimen brushes to assess treatment in nosokomial pneumonia. Am Rev Respir Dis, 147, 38-44.

[8] Fagon, J. Y., Chastre, J., Wolff, M., Gervais, C., Parer-Aubas, S., Stephan, F., Similowski, T., Mercat, A., Diehl, J.L., Sollet, J.P., Tenaillon, A. (2000) Invasive and Non-invasive strategies for management of suspected ventilator-associated pneumonia. Ann Intern Med, 132 , 621-30.

[9] American Thoracic Society. (2005) Infectious Diseases Society of America, guidelines for the management of adults with hospital-acquired, ventilator-associated and healthcare associated pneumonia. Am J Respir Crit Care Med, 171, 388-416.

[10] Tenover, F.C., Robert, D.A., Goering, R.V., Mickelsen, P.A., Murray, B.E., Persing, D.H., Swaminathan, B. (1995) Interpreting chromosomal DNA restriction fragments produced by pulsed field gel electrophoresis, Criteria for bactrerial strain typing. Clin Microbiol, 33(9), 2233-2239.

[11] Wassenaar, T.M. (2003) Molecular typing of pathogens.
Berl Munch Tierarztl Wochenschr, 116, 447-453.

[12] Le-Gall, J.R., Lemeshow, S., Saulnier, F. (1993) A new Simplified Acute Physiology Score Based on a European/ North American study. JAMA, 270, 2957-2963.

[13] Vincent, J.L., Moreno, R., Takala, J., Willats, S., De Mendonca, A., Bruining, H., Reinhart, C.K. Suter PM and Thijs LG. (1996) The SOFA (Sepsis-related Organ Failure Assessment) score to describe organ dysfunction/failure. On behalf of the Working Group on Sepsis-Related Problems of the European Society of Intensive Care Medicine. Intensive Care Med, 22, 707-10.

[14] Luna, CM., Vujacich, P., Niedermann, M.S., Vay, C., Gherardi, C., Matera, J., Jolly, E.C. (1997) Impact of BAL data on the therapy and outcome of ventilator-associated pneumonia. Chest, 111, 676-685.

[15] Luna, C.M., Aruj, P., Niederman, M.S., Garzon, J., Violi, D., Prignoni, A., Rios, F., Baquero, S. (2008) Appropriateness and delay to initiate therapy in ventilator-associated pneumonia. Eur Respir J, 27, 158-64.

[16] Giantsou, E., Liratzopoulos, N., Efraimidou, E., Panopoulou, M., Alepopoulou, E., Kartali-Ktenidou, S., Minopoulos, G., Manolas, K.I. (2007) De-escalation therapy rates are significantly higher by bronchoalveolar lavage than by tracheal aspirates. Intensive Care Med, 33, 1533-1540.

[17] Ioanas, M., Ewig, S., Torres, A. (2003) Treatment failures in patients with ventilator-associated pneumonia. Infect Dis Clin N Am, 17, 753-771.

[18] Kollef, M.H. (2007) Moving towards real-time anti-microbial management of ventilator-associated pneumonia Clin Infect Dis, 44, 388-390.

[19] Prince, A.S. (2002) Biofilms, antimicrobial resistance and airway infection. $N$ Engl $J$ Med, 347, 847-885.

[20] Dominguez, A.A., Arango, M.V., Torres, A. (2005) Treatment failure in patients with ventilator-associated pneumonia. Semin Respir Crit Care Med, 27, 104-12. 